\title{
Characterization of Single-Crystal Dendrite Structure and Porosity in Nickel-Based Superalloys Using X-Ray Micro-Computed Tomography
}

\author{
Jakub Jaroszewicz ${ }^{1, a}$, Hubert Matysiak ${ }^{2, b}$, Jakub Michalski ${ }^{3, c}$, \\ Kamil Matuszewski ${ }^{1, d}$, Krzysztof Kubiak ${ }^{4, \mathrm{e}}$ and Krzysztof Jan Kurzydlowski ${ }^{1, \mathrm{f}}$ \\ ${ }^{1}$ Warsaw University of Technology, Faculty of Materials Science and Engineering, 141 Woloska, \\ 02-507 Warsaw, Poland \\ ${ }^{2}$ Research Center "Functional Materials", Warsaw University of Technology, 141 Woloska, \\ 02-507 Warsaw, Poland \\ ${ }^{3}$ Materials Engineers Group Sp.z o. o. 141 Woloska, 02-507 Warsaw, Poland \\ ${ }^{4}$ R\&D Laboratory for Aerospace Materials, Rzeszow University of Technology, \\ 2 W. Pola, 35-959 Rzeszow, Poland \\ ajakubjaroszewicz@wp.pl, bhuba@inmat.pw.edu.pl, cj.michalski@megroup.pl, \\ dkamil.km@gmail.com, ${ }^{\mathrm{e} k r k u b @ p r z . e d u . p l,{ }^{f} k j k @ i n m a t . p w . e d u . p l ~}$
}

Key words: Tomography; Superalloys; Microstructure; Porosity

\begin{abstract}
X-ray micro-computed tomography system has been used for visualization in two- (2-D) and three dimensions (3-D) of the dendrite structure and pores in single-crystals fabricated by Bridgman investment casting technique. The system described in the paper reconstructs 3-D geometry from a set of 2-D images obtained by multiple slicing of an X-ray radiography image. The results obtained in this study demonstrate the effect of withdrawal rate on the primary dendrite arm spacing and porosity in single-crystal made of CMSX-4 alloy.
\end{abstract}

\section{Introduction}

Working conditions in advanced gas turbine engines impose extremely demanding conditions on the engineering materials used for critical components such as the blades. Nickel-based singlecrystal superalloys are widely used for the blades in the first and second stages of the turbine with their extraordinary resistance to creep being assured by lack of the grain boundaries [1]. As a result, the mechanical properties of these alloys depend on the other microstructural features, in particular the dendrites orientation, preferentially along $<001>$ crystallographic axis. Slight misalignments between neighbouring dendrites can lead to a complex network of dislocations in interdendritic regions, which are known to accelerate primary creep rate [2,3]. The creep resistance depends also on the primary dendrite arm spacing and residual porosity, which although is reduced to a low level, however, is difficult to be completely eliminated from single-crystal blades. In spite of their small size, about a few ten of microns, pores significantly deteriorate the mechanical properties, especially the fatigue lifetime [4].

In view of the above given general comments, it is no surprise that much effort has been made to provide tools for imaging the structure of single crystal blades at a submicron length scale and with an opportunity to infer its 3-D features. In this work, micro-Computed Tomography ( $\mu-\mathrm{CT})$ has been used to this end. More specifically, a desktop X-ray micro-tomography instrument was used to investigate microstructure and porosity in single-crystal nickel-base CMSX-4 superalloy. 


\section{Materials and method}

In this investigation CMSX-4 blades were directionally solidified in a Bridgman-type apparatus by investment casting. (The castings and heat treatments were carried out under a joint project conducted by the Faculty of Materials Science and Engineering of Warsaw University of Technology and Faculty of Mechanical Engineering of Technical University of Rzeszow). An example of the single crystal cast product investigated in the study is shown in Figure 1. Schematic view of the samples used in tomography measurements are shown at the right part of the figure. Some details with regard to the specimen dimensions, orientation and solidification conditions are given in Table1.

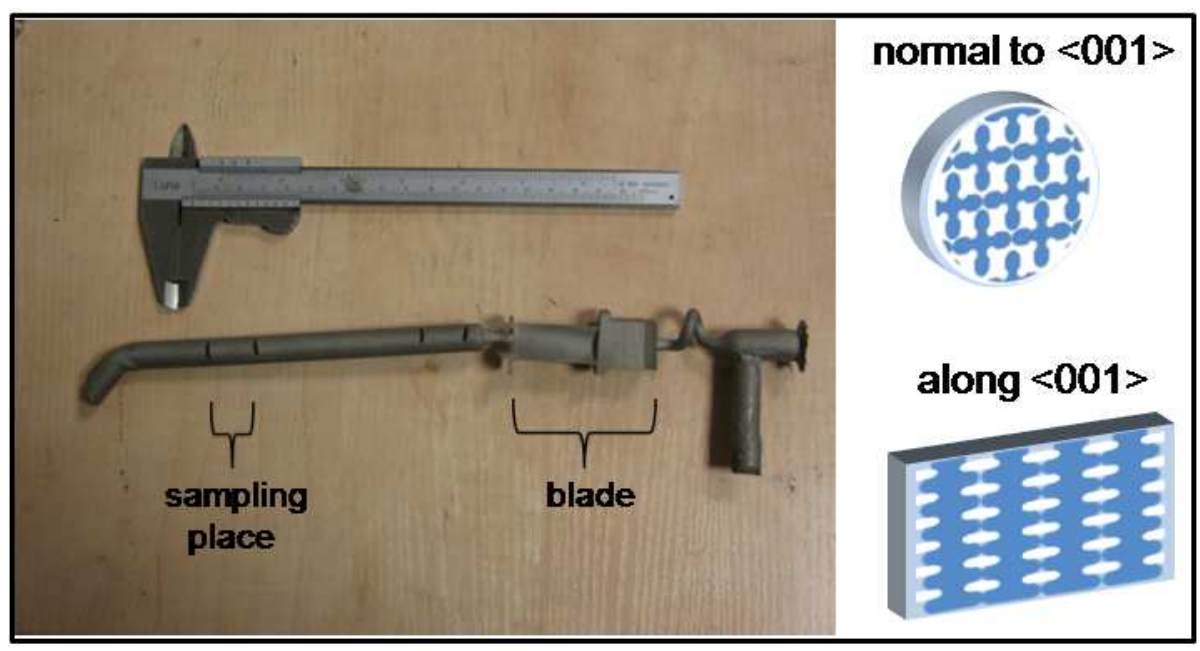

Fig. 1. A single crystal cast product used in the present study obtained by investment casting.

Table 1. Dimensions, withdrawal rate and orientation of the samples examined in the present study

\begin{tabular}{|c|c|c|c|c|c|c|}
\hline No. & $\begin{array}{l}\text { Dimension } \\
{[\mathrm{mm}]}\end{array}$ & $\begin{array}{l}\text { Diameter } \\
\text { [mm] }\end{array}$ & $\begin{array}{l}\text { Thickness } \\
{[\mu \mathrm{m}]}\end{array}$ & $\begin{array}{c}\text { Withdrawal rate } \\
{[\mathrm{mm} / \mathrm{min}]}\end{array}$ & Orientation & \\
\hline 1 & $9.5 \times 14.5$ & - & $\sim 430$ & 2 & along $<001>$ & \multirow{6}{*}{ as-cast } \\
\hline 2 & - & 9.5 & $\sim 430$ & 2 & normal to $<001>$ & \\
\hline 3 & $11.5 \times 14.5$ & & $\sim 430$ & 3 & along $<001>$ & \\
\hline 4 & - & 11.5 & $\sim 430$ & 3 & normal to $<001>$ & \\
\hline 5 & $7.5 \times 14.5$ & - & $\sim 430$ & 5 & along $<001>$ & \\
\hline 6 & - & 7.5 & $\sim 430$ & 5 & normal to $<001>$ & \\
\hline 7 & $11.5 \times 14.5$ & - & $\sim 150$ & 3 & along $<001>$ & \multirow{2}{*}{$\begin{array}{l}\text { heat* } \\
\text { treated }\end{array}$} \\
\hline 8 & - & 11.5 & $\sim 150$ & 3 & normal to $<001>$ & \\
\hline
\end{tabular}

*Solution heat treatment at $1280^{\circ} \mathrm{C}$ for $1 \mathrm{~h}$ and aging at $870^{\circ} \mathrm{C}$ for $40 \mathrm{~h}$

The samples for tomography were cut, from the part of the cast denoted as "sampling place", parallel and perpendicular to the dendrite-growth direction. They were machined into small plates via wire electrical discharge machining, and polished down to thicknesses of 150 and $430 \mu \mathrm{m}$. The "blade" part of the cast was maintained for standard NDT measurements, as the objective of this work was to verify the applicability of the desktop $\mu-\mathrm{CT}$ and studies of the blades properties are subject of a different research project. 
The samples were mounted on a dedicated sample holder and scanned by a SkyScan 1172 X-ray micro-tomography instrument. No extra sample preparation was required. The X-ray micro focus tube (tungsten reflection target) of the $\mu$-CT system was set at a voltage of $100 \mathrm{kV}$ and a current of $100 \mu \mathrm{A}$. Radiographs, with isotropic resolution of $4 \mu \mathrm{m}$ in terms of pixel/voxel size, were acquired by means of a CCD camera of $4,000 \times 2,096$ pixels. A frame averaging of 15 and a rotation step of $0.4^{\circ}$ between individual radiographs, covering a view of $360^{\circ}$, were chosen. Such measurement parameters allow for a good balance between required scan time and quality of the tomography results.

The tomography projections were processed using a modified Feldkamp cone-beam algorithm. Stack of 2D cross section images of the samples were obtained as described in [5]. The data set was analyzed with the CTAn software package and the ImageJ Java image processing software in order to create a complete $3 \mathrm{D}$ representation of the microstructure of the superalloy and to calculate the porosity $[6,7]$.

\section{Results and discussion}

$\mathrm{X}$-rays are uniquely suited for imaging the variations in the dendrite type microstructures. This is because regions with dissimilar compositions attenuate differently and this can be used to obtain images of the geometry of dendrite arms and interdendritic space. An example of such an image is given in Figure 2. The size of each projection plane was approximately $8 \mathrm{~mm} \times 6 \mathrm{~mm}$. However, the area analyzed was smaller because of the well-known tomography imaging artifacts [8]. In particular, in this case "ring" and "beam-hardening" were observed.

In the present study, for each specimen 100 slices were analyzed, each with an area of about $8 \mathrm{~mm}^{2}$. The images recorded by tomography are in general characterized by certain degree of diffusivity. In the current study, however, the grey level distributions had two clearly separated maxima, one for the pore volume and one for superalloy matrix. The sharp minimum in between was used as a threshold value in the process of transforming the live images into binary. The threshold was set at the same level for all the samples examined. Small pores with a volume below $1 \times 1 \times 1$ voxels $(64$ $\mu \mathrm{m}^{3}$ ) were considered below the resolution limit and disregarded in the analyses. Each pore emerging on the surface of the analyzed volume was removed as well. The relative reduction in the porosity, caused by such data processing, was checked to be around $1 \%$ and always below $3 \%$ of the true value.

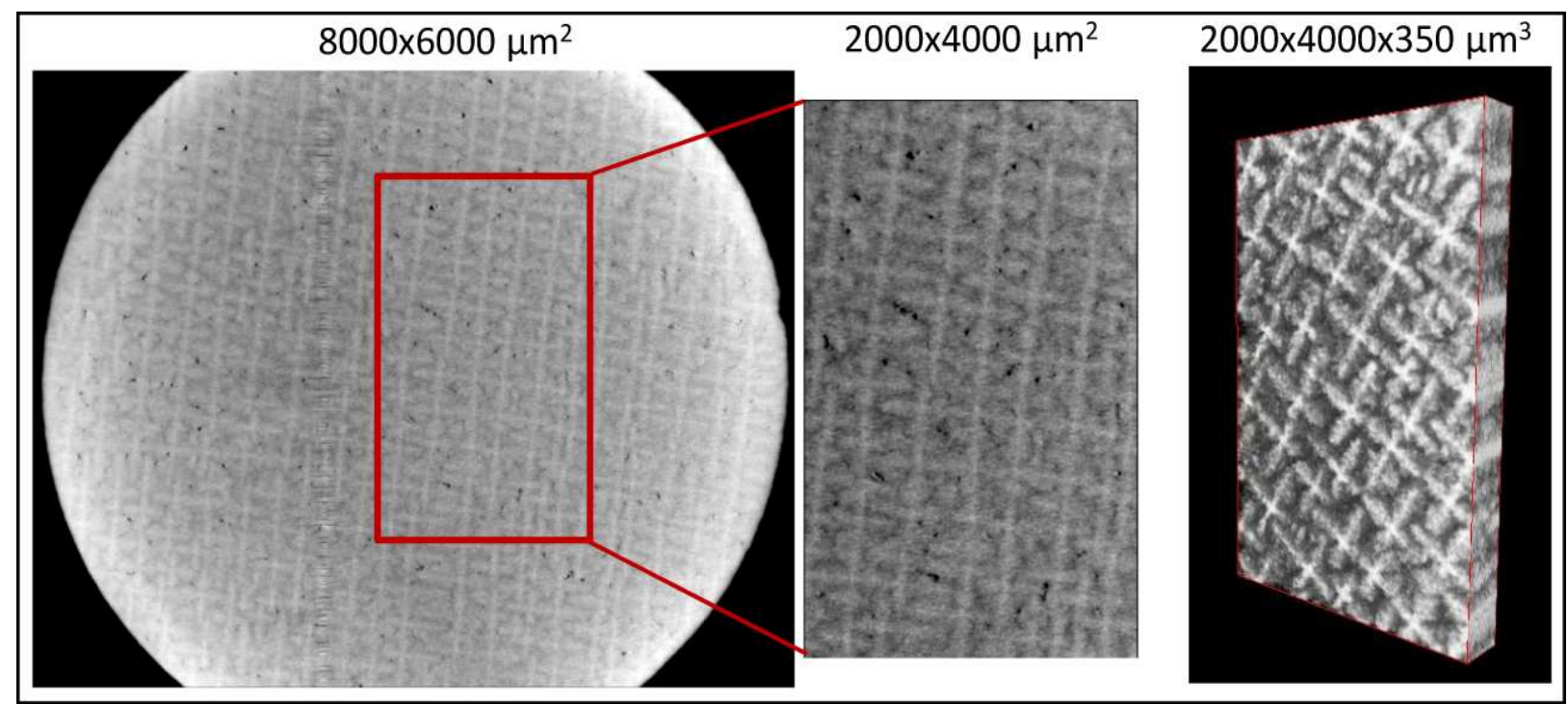

Fig. 2. An example of projection plane obtained by means of desktop $\mu$-CT revealing geometry of the dendrites in a single crystal superalloy (left). A region of interest and 3-D view of a 350 micron thick slice (centre and right). 
The current study demonstrates that the X-ray tomography can be used to quantify dendrite orientation, which in general may differ from the $<001>$ casting direction. Misalignments, on the order of degrees, between adjacent arms can be noted in the reconstructed sections parallel to the growth direction. The relative misalignment angles between 100 adjacent dendrites were measured for slices similar to the one shown in Figure 3a. The primary dendrite arm spacing was also measured for, on average, 100 dendrites examined on slices perpendicular to the withdrawal direction (similar to Fig 3b). The results of mis-orientation angles and dendrite arm spacing measured by tomography are listed in Table 2 .

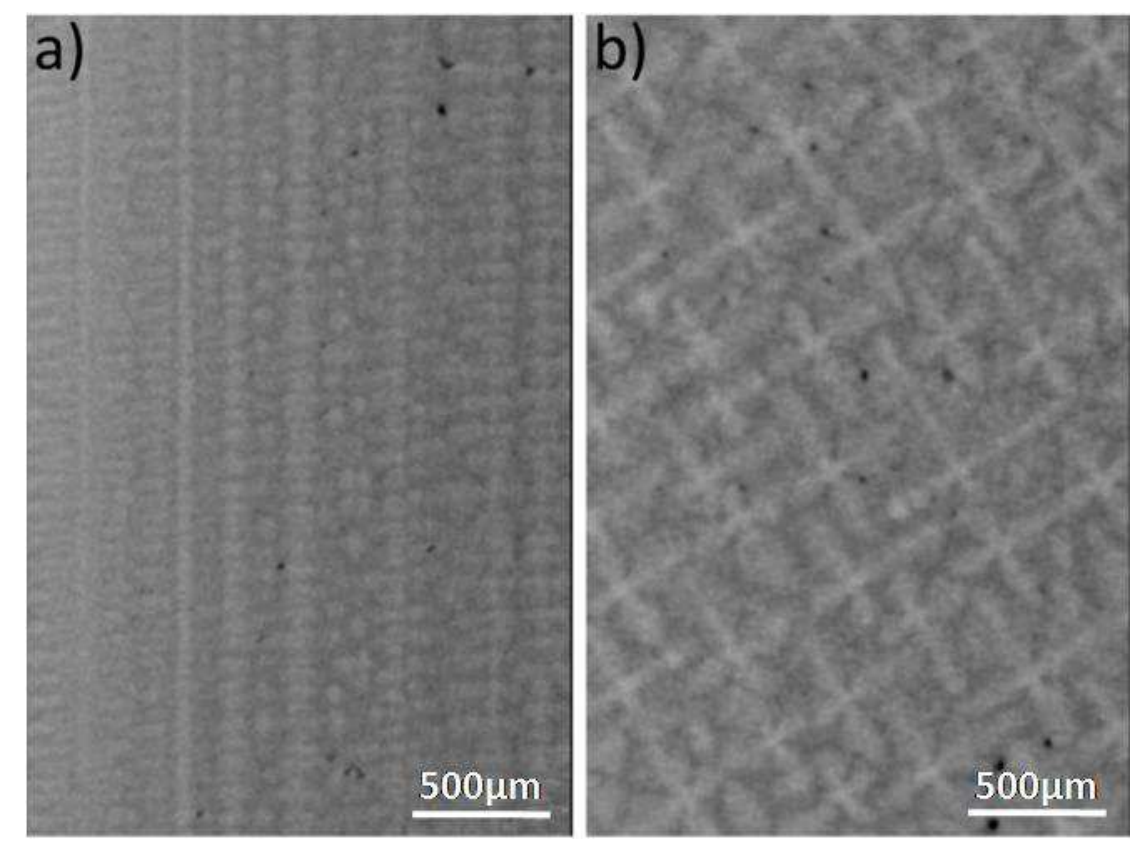

Fig. 3. Images of dendrites and interdendritic regions, light and dark areas respectively:

a) along the casting direction, b) normal to the casting direction.

The results of measurements of the mis-orientation angles suggest that during the solidification process employed in this study, the dendrites grow with slight crystallographic misalignment accommodated by dislocations within the interdendritic region. This misalignment on average increases with at higher withdrawal rate, while the primary dendrite arm spacing decreases.

Table 2. The average values of primary dendrite arm spacing and mis-orientation angles calculated for over 100 dendrites investigated with X-ray tomography

\begin{tabular}{|c|c|c|}
\hline $\begin{array}{c}\text { Withdrawal rate } \\
{[\mathbf{m m} / \mathbf{m i n}]}\end{array}$ & $\begin{array}{c}\text { Dendrite arm } \\
\text { spacing }[\boldsymbol{\mu m}]\end{array}$ & $\begin{array}{c}\text { Mis-orientation } \\
\text { [degrees] }\end{array}$ \\
\hline 2 & $386(35 \mathrm{SD})$ & 3.4 \\
\hline 3 & $357(26 \mathrm{SD})$ & 4.6 \\
\hline 5 & $358(38 \mathrm{SD})$ & 5.4 \\
\hline \multicolumn{2}{|l}{} \\
\hline
\end{tabular}

The imaging method proposed here can also be used to investigate the residual porosity. This porosity was investigated for a series of samples using image processing illustrated in Figure 4. As explained earlier, grey level threshold value was set as equal to the minimum between the grey level of the matrix and pore. 


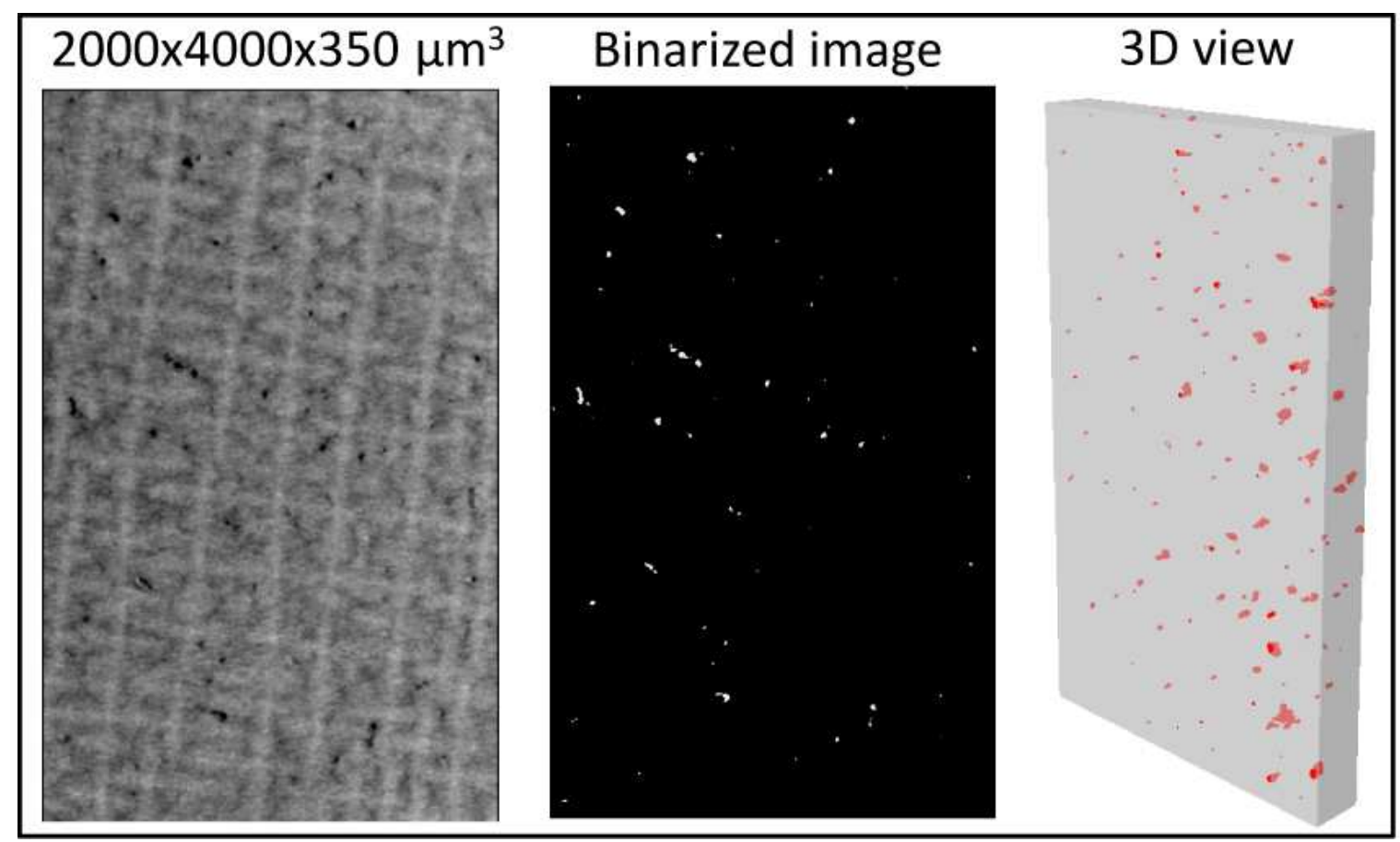

Fig. 4. Examples of the images revealing the dendrite structure of a single crystal superalloy (left), binary image of pores (centre) and a 3-D view of their spatial arrangement (right)

The results of the pore imaging and size measurements are listed in Table 3. It can be noted that the pores, as expected, are concentrated in the interdendritic regions (see Fig. 5). It has been also found that the porosity decreases with the increasing withdrawal rate (Tab. 3). The possible explanation of this finding is that the pores form with the rate, which depends on the size of the interdendritic zones. The pore nucleation rate being slower in the fine dendrite structures has been explained by Lamm and Singer [9], who investigated the change in the porosity with the solidification conditions.

Table 3. Porosity and pore equivalent diameter measured via X-ray tomography for the samples casted under the varying withdrawal rate

\begin{tabular}{|c|c|c|c|}
\hline $\begin{array}{c}\text { Withdrawal rate } \\
{[\mathbf{m m} / \mathbf{m i n}]}\end{array}$ & $\begin{array}{c}\text { Porosity } \\
{[\mathbf{\%}]}\end{array}$ & $\begin{array}{c}\text { Diameter, d2 } \\
{[\boldsymbol{\mu} \mathbf{m}]}\end{array}$ & \\
\hline 2 & 0.13 & 29 & \multirow{2}{*}{ as-cast } \\
\hline 3 & 0.094 & 26 & \\
\hline 5 & 0.075 & 20 & heat treated \\
\hline 3 & 0.21 & 20 & \\
\hline
\end{tabular}

The imaging and measurements were also curried out for the samples of CMSX-4 subjected to heat treatment. An interesting result is, that the heat treatment brings about an increase of the porosity and reduction in their size. This observation is in agreement with the earlier work of Bokstein et al. [10], who showed that the heat treatment results in concurrent annihilation of pre-treatment porosity and nucleation of new pores. 


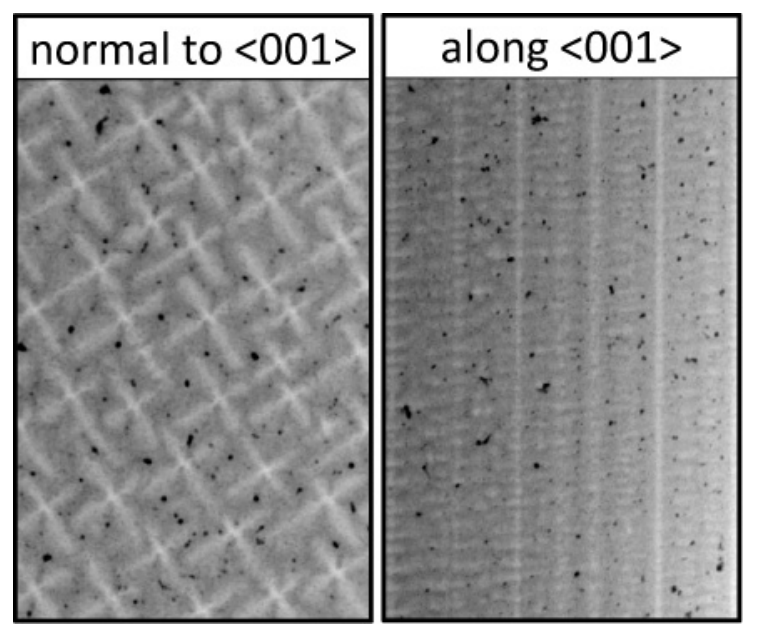

Fig. 5. Superimposed images from the reconstructed slices which illustrate that the pores are primarily located in the interdendritic regions.

\section{Conclusions}

The results presented in the paper clearly demonstrate that desktop X-ray tomography is a promising technique investigations of single-crystal microstructures and porosity in nickel-base superalloys. In particular, it can be used to obtain quantitative information on the size of dendrite arm spacing and misalignments between neighbouring dendrites.

The results presented here also show, that the technique can be used to image and measure pores in single-crystal blades and their transformation induced by the applied heat treatment. For detailed analysis of the small pores, however, an improvement of the spatial resolution is desirable. Acknowledgements

The present study was financed from resources of MNiSzW as part of the PBZ-MNiSW-03/I/2007 project.

\section{References}

[1] H. Moustapha, M. F. Zeleski, N. C. Baines and D. Japikse: Axial and Radial Turbines, Concepts NREC, White River Junction, Vt, USA, 2003.

[2] T. M. Pollock and A. S. Argon: Acta Metall. Mater. Vol. 40 (1992), p. 1.

[3] N. S. Husseini, D. P. Kumah, J. Z. Yi, C.J. Torbet, D. A. Arms, E. M. Dufresne, T.M. Pollock, J. W. Jones, R. Clarke: Acta Mater. Vol. 56 (2008), p. 4715

[4] K. P. Fullagar, R. W. Broomfield, M. Hulands, K Harris, G. L. Erickson, and S. L. Sikkenga; International Gas Turbine and Aeroengine Congress and Exposition (1994), p. 1

[5] L.A. Feldkamp, L.C. Davis, J.W. Kress: J. Opt. Soc. Am. A Vol. 1 (1984), p. 612

[6] Information on http://www.skyscan.be

[7] Information on http://rsbweb.nih.gov/ij/

[8] J.F. Barrett, N. Keat: RadioGraphics Vol. 24 (2004), p. 1679

[9] M. Lamm and R.F. Singer: Met. Mat. Trans. A Vol. 38 (2007), p. 1177

[10] B.S. Bokstein, A.I. Epishin, T. Link, V.A. Esin, A.O. Rodin and I.L. Svetloy: Scripta Mater. Vol. 57 (2007), p. 801 